\title{
FIRMA DIGITAL UTILIZACIÓN DE LA FIRMA DIGITAL EN EL ÁMBITO NOTARIAL ${ }^{1}$
}

\author{
DIGITAL SIGNATURE \\ USE OF THE DIGITAL SIGNATURE IN THE NOTARIAL AREA
}

Por Dolores Gras ${ }^{(*)}$

\begin{abstract}
Resumen: Este artículo estudia el impacto de la firma digital en el ámbito notarial, para lo cual se conceptualiza la institución, y su forma de funcionamiento en el Sistema Argentino, tanto desde el punto de vista técnico para entender cómo funciona, requisitos legales, sus efectos y limitaciones, como así también intentar comprender la seguridad que brinda este medio de expresión de voluntad. Igualmente se analiza su impacto en el ámbito notarial y sus consecuencias en los negocios celebrados con este instituto.
\end{abstract}

Palabras Claves: Derecho notarial - firma digital - firma electrónica

\begin{abstract}
This paper studies the impact of the digital signature on the notarial scope, for which the institution is conceptualized, and its way of functioning in the Argentine System, both from the technical point of view to understand how it works, legal requirements, its effects and limitations, as well as trying to understand the security provided by this means of expression of will. Likewise, its impact on the notarial scope and its consequences in the businesses celebrated with this institute are analyzed.
\end{abstract}

Keywords: Notarial right - digital signature - electronic signature

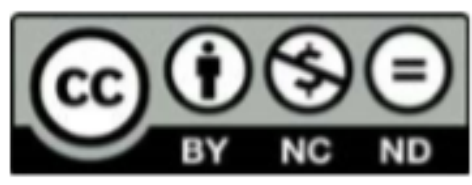

Artículo publicado bajo Licencia Creative Commons Atribución-No Comercial-Sin

Derivar. (C) Universidad Católica de Córdoba

DOI http://dx.doi.org/10.22529/adc.2019(13)07

\footnotetext{
${ }^{1}$ Artículo recibido el 21 de septiembre y aprobado para su publicación el 5 de diciembre de 2019.

(*) Abogada y notaria por la Universidad Blas Pascal. Finalizando Maestría de Derecho Notarial, Registral e Inmobiliario en la Universidad Notarial Argentina, cursando segundo año de Maestría en Derecho Empresarial en la Universidad Blas Pascal, entre otros cursos de Posgrado para sostener una formación continua. Actualmente me desempeño como abogada de distintas sociedades a fin de brindar asesoramiento integral vinculado a distintas ramas del derecho. Mail de contacto: dologras@ hotmail.com
}

\begin{tabular}{llll}
\hline \hline ANUARIO DE DERECHO CIVIL & TOMO XIII & 2019 & Página 121
\end{tabular}




\section{UTILIZACIÓN DE LA FIRMA DIGITAL EN EL ÁMBITO NOTARIAL}

\section{INTRODUCCION}

El código Civil y Comercial establece en el segundo párrafo del Art. 288 lo siguiente: “En los instrumentos generados por medios electrónicos, el requisito de la firma de una persona queda satisfecho si se utiliza una firma digital que asegura indubitablemente la autoría e integridad del instrumento". Así deja en claro que la firma ológrafa y la firma digital son equivalentes. Ahora bien, la firma digital debe cumplimentar con ciertos requisitos para ser equiparada a la firma ológrafa, salvo excepciones en los cuales no podrá utilizarse.

La firma digital tuvo lugar en nuestra legislación con la sanción de la ley $\mathrm{N}^{\circ} 25506$ dictada en el año 2001, donde están regulados los requisitos, efectos, distinciones, etc. Actualmente nuestro código la incorpora, y aclara algunas dudas sobre su alcance y efectos.

\section{2- FIRMA DIGITAL}

2) A. ¿Qué es la firma digital, y cómo funciona?

Con la utilización de medios digitales para la celebración de actos jurídicos, surge la necesidad de identificar al sujeto que emite la declaración de voluntad, es decir la autoría, para poder atribuirle tal manifestación y por ende los efectos jurídicos derivados de ella. Asimismo, también surge la necesidad de garantizarle al destinatario que la información llegue tal cual se la ha enviado, que no hay ninguna modificación desde que se ha firmado el documento hasta la recepción del mismo, a lo que se llama la integridad del documento.

La firma digital plasmada en el documento deberá satisfacer los requisitos exigidos por la ley para ser considerada como tal y por lo tanto gozar de las presunciones de autoría, integridad e identidad del remitente, elementos que dotarán de seguridad jurídica al mismo. El Art. 2 de la ley establece que, "se entiende por firma digital al resultado de aplicar a un documento digital un procedimiento matemático que requiere información de exclusivo conocimiento del firmante, encontrándose ésta bajo su absoluto control. La firma digital debe ser susceptible de verificación por terceras partes, tal que dicha verificación simultáneamente permita identificar al firmante y detectar cualquier alteración del documento digital posterior a su firma". Podría entenderse entonces como aquel 


\section{UTILIZACIÓN DE LA FIRMA DIGITAL EN EL ÁMBITO NOTARIAL}

procedimiento matemático que le aporta a los documentos digitales las mismas propiedades que la firma manuscrita. Dicho procedimiento matemático implica una infraestructura donde hay distintos componentes y procedimientos, para obtener la firma digital. Técnicamente hablando será el resultado de haber aplicado una ecuación matemática, basada en procedimientos tecnológicos, conocido como un sistema de encriptación asimétrica que parte de un algoritmo matemático (conjunto ordenado de operaciones complejas compuesta por varios datos numéricos).

Ésta firma estará compuesta por dos claves, una de ellas será de dominio privado y otra será de dominio público. Al momento de la solicitud de creación de una firma digital, el algoritmo será completado por determinados números concretos que permitirá obtener un número específico y único perteneciente al solicitante, que generará ambas claves. A cada clave privada, le pertenece una clave pública, estrechamente vinculadas. Es decir que no existen dos firmas digitales iguales.

A su vez, quien decida hacer uso de la firma digital deberá tener instalado en el ordenador por el cual se emitirá el documento un software para la utilización de la misma. Con el ingreso de la clave privada restamparla firma digital en el documento. Esta clave deberá ser absolutamente confidencial, ya que su utilización significa la manifestación de la voluntad incorporada a un documento electrónico; mientras que la clave pública será la que deber otorgarse al receptor del documento a los fines de que la utilice para verificar la autoría e integridad del mismo.

De este modo el titular de la firma la obtendrá de un ente autorizado como certificador. Una vez que se haya firmado el documento, el mismo será enviado al receptor, y el receptor deberá contar también con el software de firma digital, ya que deberá ingresar la clave pública del emisor, y de esta forma podrá hacer la verificación del proceso de seguridad para controlar que el certificado haya estado vigente al momento de firmar y que el obligado autor coincida con la titularidad del certificado. Asimismo, se controla en el mismo proceso que el documento no haya sufrido cambios desde que se firmó.

Nuestro derecho hace una distinción entre firma digital y firma electrónica. La firma electrónica vendría a ser el género y la firma digital la especie. En el Art. 5 de la ley se regula la firma electrónica "Se entiende por firma electrónica al conjunto de datos electrónicos integrados, ligados o asociados de manera lógica a otros datos electrónicos, utilizando el signatario como su medio de identificación que carezca de algunos de los requisitos legales para ser considerado firma digital. 


\section{UTILIZACIÓN DE LA FIRMA DIGITAL EN EL ÁMBITO NOTARIAL}

En caso de ser desconocida la firma electrónica corresponde a quien la invoca acreditar su validez". Es decir que, en caso de que no se cumpla con los requisitos exigidos por el Art. 9para que la firma sea considerada digital, estaríamos simplemente frente a una firma electrónica. Los requisitos necesarios exigidos para una firma tenga los efectos propios de firma digital son: : 1 . Haber sido creada durante el período de vigencia del certificado digital válido del firmante; 2 . ser debidamente verificada por la referencia a los datos de verificación de firma digital indicados en dicho certificado según el procedimiento de verificación correspondiente; 3.Que dicho certificado haya sido emitido o reconocido, según el artículo 16 de la presente, por un certificador licenciado. Es importante establecer la diferencia entre ambas, ya que la carga probatoria no será la misma, en el caso de la firma electrónica quien la evoque deberá acreditar su validez.

\section{B) Procedimiento para la obtención de la clave}

El certificado digital es aquel que le permitirá al solicitante obtener la firma digital propiamente dicha. A su vez, este certificado que se obtiene como se ha mencionado supra permitirá al receptor del documento electrónico firmado verificar la autoría, es decir que quien dice firmar sea realmente esa persona que dice ser, ya que dicho certificado da fe de la vinculación entre una clave pública y un individuo o persona jurídica. Es un archivo digital, que asocia una clave pública con la identidad de su propietario.

El ente regulador de otorgamiento de certificados en la República Argentina es la Oficina Nacional de Tecnologías de la Nación (ONTI). Esta oficina nacional autoriza a certificantes públicos o privados, que son personas jurídicas conocidas como autoridades de registro.

Generalmente se solicita el certificado en un primer momento de forma online y comienza un proceso de empadronamiento donde se deben completar ciertos datos. Luego se presenta el solicitante ante el oficial de registro con la documentación para validar la persona o representante legal. Aquí se toma foto y huella digital. Una vez cumplimentado estos pasos, en caso de aprobación, se emite el certificado y se generan las claves. Para que el certificado sea considerado valido, el Art. 14 de la ley, exige que el mismo sea emitido por un certificador licenciado, que cumpla con estándares reconocidos internacionalmente. Éste deberá contener los siguientes datos (como mínimo): aquellos que permitan la individualización del sujeto, esto es datos personales del 


\section{UTILIZACIÓN DE LA FIRMA DIGITAL EN EL ÁMBITO NOTARIAL}

titular (nombre y apellido, nacionalidad, cuil y país de residencia), y también datos del certificador licenciado; deberá tener el periodo de vigencia, y solo será válida la firma digital que se aplique dentro de ese periodo, es importante que la fecha conste en el mismo para que pueda ser verificable por el receptor. Por último, deberá tener la verificación de la firma digital agregada al documento electrónico.

La finalidad que persiguen estos certificados es generar la confianza suficiente en la legitimidad de la cave publica, evitando el fraude o falsa representación. El requirente deberá instalar un software en su propia computadora para generar las claves, generándose luego el certificado que contendrá la clave pública.

Aquellas firmas que provengan de certificadores domiciliados en el extranjero serán válidos, siempre y cuando cumpla con los requisitos y procedimientos exigidos por la ley para los certificadores domiciliados en el país y además deberá existir un acuerdo de reciprocidad firmado por la República Argentina con el país de origen de la entidad certificadora.

\section{C) Verificación de autoría e integridad del documento}

La persona para firmar su documento deberá ingresar su clave privada y remitirlo al receptor, junto con el certificado de clave pública. Al momento que ingrese su clave privada en el documento obtendrá un valor hash que se expresará mediante un número específico. Una vez recibido éste deberá colocar la clave pública y así podrá descifrar la firma digital, obteniendo a su vez un valor hash. Se entiende por hash al algoritmo matemático que se utiliza como herramienta para detectar cualquier alteración que sufra el documento desde la estampa de la firma digital, a los fines de comprobar la integridad del mismo.

El receptor del mensaje va a aplicar al documento que recibió el mismo algoritmo que utilizo el emisor del documento y obtendrá un determinado valor. Si los hash de ambos coinciden el mensaje es íntegro, que quiere decir que no ha sufrido ninguna modificación desde que se colocó la firma. Por el contrario, si los números no coinciden, esto significará que el documento ha sido modificado. La importancia del procedimiento radica en que gracias a la complejidad matemática que utiliza la fórmula, no es posible adivinar la clave privada a través de la clave pública. 


\section{UTILIZACIÓN DE LA FIRMA DIGITAL EN EL ÁMBITO NOTARIAL}

Los certificados no garantizan de forma absoluta e inequívoca la autoría, ya que al ser en soporte digital el resguardo de la firma digital está en una computadora, notebook, etc, y cualquier persona podría llegar a ingresar. Por esta razón, la tecnología ha desarrollado otras herramientas de seguridad alrededor de la firma digital, para brindar aun mayor complejidad al sistema, tales como generar una clave de acceso al soporte de firma digital que sólo sea conocida por la persona titular de la firma; el dispositivo externo llamado token que se conecta al ordenador sólo cuando la persona quiere hacer uso del programa que contiene la firma digital.; o el soporte que funciona como una tarjeta electrónica que funciona de forma similar al token.

\section{D) Efectos}

Los principales principios jurídicos son tres: autenticación ya que indica al firmante; el no repudio haciendo referencia a la autoría del documento digital, la cual en principio no puede negarse; y por último, la integridad, en cuanto garantiza la inalterabilidad del documento.

En cuanto a la integridad del mismo, este principio se encuentra presente en el Art. 7 de la ley" Se presume, salvo prueba en contrario, que toda firma digital pertenece al titular del certificado digital que permite la verificación de dicha firma". Y el Art 10 establece que "Cuando un documento digital sea enviado en forma automática por un dispositivo programado y lleve la firma digital del remitente se presumirá, salvo prueba en contrario, que el documento firmado proviene del remitente”. En virtud de estos artículos se presume que la firma digital le pertenece al titular del certificado, más la presunción de que quien envía el documento es el remitente si lo hace desde el dispositivo que está programado con el sistema informático. De estas dos presunciones se extrae el principio de no repudio, que le atribuye la autoría de los documentos firmados al titular de esa firma.

Por otro lado, hablamos de integridad del documento, legislado en el Art. 8 de la ley al establecer que "Si el resultado de un procedimiento de verificación de una firma digital aplicado a un documento digital es verdadero, se presume, salvo prueba en contrario, que este documento digital no ha sido modificado desde el momento de su firma" y el Art. 288 del CCYC al establecer que "la firma prueba la autoría de la declaración de voluntad expresada en el texto al cual corresponde. Debe consistir en el nombre del firmante o en un signo. En los instrumentos generados por medios 


\section{UTILIZACIÓN DE LA FIRMA DIGITAL EN EL ÁMBITO NOTARIAL}

electrónicos, el requisito de la firma de una persona queda satisfecho si se utiliza una firma digital, que asegure indubitablemente la autoría e integridad del instrumento".

El documento viaja por internet con las medidas de seguridad necesarias para garantizar que en el camino su contenido no sufra ninguna alteración, y que si ello ocurriese el destinatario podría reconocer que sufrió modificaciones. En efecto, la firma digital permite que cualquier alteración ya sea hasta un punto o una coma que se haya quitado o agregado al documento, los elementos propios del sistema pueden detectarlo y de esta forma proteger el documento dotándolo de garantía frente a cualquier alteración.

Ahora bien, la ley se ha encargado de establecer una similitud entre la firma ológrafa y la firma digital al establecer que en aquellos casos que se requiera una firma manuscrita, también queda cumplimentada la exigencia cuando se firme digitalmente, salvo en aquellas excepciones establecidas por ley. Es decir que no podrá utilizarse para: disposiciones por causa de muerte; actos jurídicos del derecho de familia; actos personalísimos en general; los actos que deban ser instrumentados bajo exigencias o formalidades incompatibles con la utilización de la firma digital, ya sea como consecuencia de disposiciones legales o acuerdo de partes.

Estos mecanismos son distintos, pero son asimilables. Ambas firmas se diferencian en que la firma ológrafa es inseparable de su autor, y la firma digital es un mecanismo separado, pudiendo ser utilizado por una persona distinta a la de su autor. Por este motivo el titular del certificado tiene la obligación por ley de mantener bajo su custodia y control exclusivo sus datos de firma digital, así como solicitar la revocación del certificado ante cualquier sospecha de que el mismo ya no se encuentra bajo su exclusiva custodia o de que alguien más conozca o pudiere conocer dichos datos.

En cuanto a la fecha y hora que se firma el documento el sistema actual no permite asegurarlo porque el programa toma la que figura en la PC, pudiendo consignar datos distintos a los reales modificando fecha y hora del mismo. Para garantizar la fecha y hora, se debería usar lo que se conoce como "el sellado de tiempo". Es un servicio adicional a la firma digital que se propuso en la DA 927 de 2014, pero que aún no tiene aplicación en nuestro país debido a que ningún ente tiene homologado el programa TSA (Timestamping Authority) porque no existe una hora oficial digital en nuestro país por el momento. 


\section{UTILIZACIÓN DE LA FIRMA DIGITAL EN EL ÁMBITO NOTARIAL}

\section{E) Actuación notarial, documentos digitales y firma digital}

Hasta aquí ha quedado en claro que la utilización de la firma digital sirve para contrataciones privadas entre ausentes. Pero surge la duda si esta firma podría llegar a implementarse por escribanos en ejercicio de sus funciones. Sabemos que el escribano es un profesional del derecho que ejerce una función pública que mediante su actuación dentro de los límites de la ley dota de autenticidad lo que ocurre ante él, es decir que suministra fe pública, brindando seguridad jurídica a los documentos en los que interviene.

Para desarrollar dicha tarea, una de las actividades más importantes es la de la individualización de los sujetos; tiene el deber de identificarlos actuando con diligencia y cautela.

La nueva tecnología está obligando a los notarios a reestructurar el desarrollo de sus actividades, pero hay que tener en cuenta que no se puede alejar de su prestación personal, ya que esto garantiza la seguridad jurídica del acto en el cual intervino.

Recientemente están comenzado a aparecer de forma progresiva algunas innovaciones en cuanto a la utilización de la firma digital por escribanos. Una de la últimas novedades de nuestra legislación ha sido dispuesta por el decreto 434/16 del plan de modernización del estado nacional y el decreto1063/16 del poder ejecutivo nacional donde se aprobó la implementación de trámites a distancia en el ámbito nacional con el sistema de gestión documental electrónica como medio de interacción entre el ciudadano y la administración pública, a través del cual se recepta y remiten por medios electrónicos presentaciones, solicitudes, escritos, notificaciones, etc. Lo que importa a los fines del presente es el artículo 14 del decreto en el cual se establece que los certificadores licenciados de organismos públicos pueden constituir autoridades de registros pertenecientes al sector privado previa autorización de la secretaria de modernización administrativa del ministerio de modernización, con esta facultad la ONTI concedió a los colegios de escribanos del país a que sean autoridades de registro de los certificados de firma digital emitidos para los escribanos de cada jurisdicción. De esta forma los escribanos pueden contar con los mismos certificados de firma digital que utiliza la administración pública federal para sus actuaciones. Así, los distintos colegios deberían hacer los trámites necesarios para constituirse en autoridades de registro y así poder otorgar a sus colegiados los certificados correspondientes, y así podrían utilizar la firma digital para comunicaciones entre otros entes públicos, entre escribanos, etc. 


\section{UTILIZACIÓN DE LA FIRMA DIGITAL EN EL ÁMBITO NOTARIAL}

Ahora bien, surge la duda si podría implementarse la firma digital en escrituras públicas, como así también la implementación de un protocolo notarial en soporte digital.

Este tema ha sido discutido en la asamblea de la unión internacional del notariado celebrado en Budapest en el año 2014, donde se arribaron a las siguientes conclusiones. Se estableció que la utilización de la firma digital no facilita la tarea del notario ya que su utilización rompe la llamada cadena de autenticidad, alegando que el notario debería rechazar todos aquellos sistemas de otorgamiento que no comporten la inmediación del notario en el lugar y momento de celebración del negocio. Es decir que uno de los principios básicos de la actividad del notario es la del principio de inmediación del otorgamiento. Entonces si decimos que indudablemente las partes deben estar presentes ante el notario, entonces la utilidad y la efectividad de la firma digital pierde sentido. Por esta razón es que surge el concepto de la firma hológrafa digitalizada, como un mecanismo intermedio entre la firma hológrafa y la firma digital. Aquí podríamos hablar de un protocolo notarial que sea digital donde la autoría y la inalterabilidad del documento quedarían en cabeza del notario como autor del documento. Esta firma consiste en que el sujeto firme en un dispositivo digital conectado a un ordenador que contiene el documento digital. Así la firma se plasmaría directamente en el documento. Con la utilización de este medio se obtendría un documento notarial que sea digital, sin dañar la seguridad jurídica brindada por los notarios. Para esto debería implementarse un sistema de seguridad para el almacenamiento del protocolo de seguridad, el cual debería estar compuesto de un conjunto de reglas y formatos.

De esta forma, y a su vez con la utilización de la firma digital por parte del escribano la asamblea concluyó que podría pensarse en la posibilidad de un sistema de circulación y comunicación electrónica del documento. Así podrían circular las copias de la matriz, por ser el escribano el que hace la manifestación de que la copia del instrumento es auténtica al original. En el congreso se propuso entonces que la copia electrónica de la escritura sea la que se convierta en el instrumento habitual para causar las inscripciones registrales.

En nuestra legislación, específicamente en el Art. 299 del CCYC advierte que la escritura pública debe extenderse en el protocolo del escribano, pero no establece una directiva del soporte material que debe tener las copias o testimonios de aquellas. Esto implica que las legislaciones de cada provincia podrían extender la utilización de un soporte electrónico notarial para la 


\section{UTILIZACIÓN DE LA FIRMA DIGITAL EN EL ÁMBITO NOTARIAL}

formalización de las copias o testimonios de las escrituras públicas. El problema surgiría en distinguir entre la primera o segunda copia, ya que en los formatos digitales no se distingue entre originales y copias, etc por esta razón el congreso internación del notariado de parís del año 2016 estableció que "para evitar la posibilidad de multiplicar ad infinitum las copias de la copia electrónicas...se recomienda que las copias electrónicas con valor jurídico de documento autentico equivalente a las correspondientes en soporte papel solamente puedan ser remitidas a otros notarios, autoridades judiciales o funcionarios de la administración, que tales copias electrónicas solamente puedan pasarse a soporte papel por el propio notario autorizante, el notario destinatario o el funcionario parte de los expedientes administrativos".

\section{F) Derecho comparado: Legislación Española}

El Derecho español ha avanzado mucho respecto del uso de la tecnología y la incorporación de la firma digital. Específicamente para los notarios españoles se les ha simplificado la tarea, y se ha establecido que deben contar con una firma digital notarialmente. Ellos le llaman firma electrónica, pero aquí es similar a la firma digital. Dicha firma es conocida con el nombre de FEREN, que significa Firma Electrónica Reconocida Notarial.

Todos los notarios tienen una firma digital que está expedida por el Consejo General del Notariado Español, la misma tiene el carácter exclusivo de firma digital notarial ya que es utilizado solo a los fines de suscripción de documentos públicos u oficiales propios del ejercicio de las funciones notariales. Asimismo, se utiliza para hacer presentaciones en los distintos registros (registro de la propiedad, mercantil o de bienes muebles) expedidos con la firma electrónica del notario autorizante o responsable del protocolo.

En cuanto a las copias de las matrices, las mismas pueden expedirse y remitirse digitalmente mediante la implementación de la firma digital del notario interviniente. Las mismas solo podrán hacerse circular a otro notario, registrador u órgano de administración pública o jurisdiccional; pero las copias simples podrán hacerse circular siempre que se remitan al interesado que tenga interés legítimo. Por su parte aquellas copias que han sido expedidas electrónicamente, si son requeridas formato papel a los fines de que conserven la autenticidad y garantía notarial, sólo podrá hacerlo el notario al que se le hubiese remitido. 


\section{FIRMA DIGITAL UTILIZACIÓN DE LA FIRMA DIGITAL EN EL ÁMBITO NOTARIAL}

\section{CONCLUSION}

Queda claro a partir de la sanción del código civil y comercial de la nación el reconocimiento de los medios electrónicos como medios válidos que tienen plena eficacia en el mundo jurídico otorgándole el mismo valor probatorio.

La firma digital es equivalente a la firma ológrafa en aquellos casos que la ley así lo permite, por lo que no deberían quedar dudas sobre la seguridad jurídica que ésta otorga cuando se decide utilizarla. Los documentos están dotados de autoría e integridad.

En las relaciones privadas la firma digital es equivalente a la firma ológrafa. Pero no es lo mismo en el ámbito notarial ya que la presencia del notario es fundamental en la actuación, por lo que pienso que no sería conveniente que se utilice la firma digital tal como la conocemos hoy, ya que la misma es eficaz para negocios jurídicos entre ausentes (más allá de las implementaciones en los sectores públicos como la administración pública). Pero esto no implica que los escribanos deban quedarse atrás con la modernización de las formas de trabajo. A mi modo de ver la legislación debe ir acompañando los cambios, ya que la realidad siempre avanza más rápido que el derecho, por lo que debe regular las diferentes situaciones que se presentan. Debería implementarse una nueva forma que acompañe la utilización de firmas digitales, expedida por el colegio de escribanos que permita la comunicación entre los profesionales y los sectores públicos, como así también pensar en la posibilidad de la utilización de un protocolo notarial electrónico. 